\title{
Identification and characterization of cyclotides from Brazilian Psychotria species
}

\author{
Meri Emili Pinto, Mariana Rosa, Vanderlan Bolzani, Eduardo Cilli
}

Sao Paulo State University, Brazil

https://doi.org/10.17952/35EPS.2018.238

Psychotria genus below to tribe Psychotrieae (Rubiaceae) and comprises approximately 2,000 species[1]; some of them are reported as cyclotide-containing plant species[2,3]. Cyclotides are characterized by a head-to-tail cyclized backbone usually composed of 28-37 amino acids, and a unique knotted disulfide topology involving six conserved cysteine residues termed the cyclic cystine-knot (CCK) motif[4,5]. The CCK motif is responsible for their exceptional resistance to chemical, enzymatic and thermal degradation[6]. This topology confers them remarkable stability and wide range of biological and/or therapeutic applications, between them, anti-HIV, anthelmintic, insecticidal, molluscicidal, antimicrobial, uterotonic, cytotoxic, hemolytic, trypsin inhibitory, and immunosuppressive activities. This work deals with the identification and characterization of cyclotides accumulated in the Brazilian plant species: Psychotria vellosiana (stems and leaves) and Psychotria leiocarpa (aerial parts).

Dried and pulverized stems and leaves from $P$. vellosiana and aerial parts from $P$. leiocarpa were extracted with $\mathrm{CH}_{3} \mathrm{OH}-\mathrm{H}_{2} \mathrm{O}(6: 4, \mathrm{v} / \mathrm{v})$ at room temperature 4 times over a period of $24 \mathrm{~h}$. The extract was partitioned with $\mathrm{CH}_{2} \mathrm{Cl}_{2}-\mathrm{CH}_{3} \mathrm{OH}-\mathrm{H}_{2} \mathrm{O}(1: 1: 1, \mathrm{v} / \mathrm{v} / \mathrm{v})$ (4 times) and the aqueous phases were separated and concentrated on a rotary evaporator prior to freeze drying, yiel ding what is further referred to as aqueous extract. The aqueous extracts were dissolved in $\mathrm{CH}_{3} \mathrm{CN}-\mathrm{H}_{2} \mathrm{O}(1: 9 ; \mathrm{v} / \mathrm{v})$ and immediately used for solid-phase extraction (SPE). $\mathrm{C}_{18}$ SPE cartridge (Strata-Phenomenex $\mathrm{C}_{18} 55 \mu \mathrm{m}, 70,500 \mathrm{mg}$ ) were activated with $\mathrm{CH}_{3} \mathrm{OH}$ and subsequently equilibrated with aqueous $0.1 \%$ trifluoroacetic acid. After application of the extracts, the cartridge was washed with mixtures of buffer A ( $0.1 \%$ aqueous trifluoroacetic acid) in B (90\% acetonitrile, $0.08 \%$ trifluoroacetic acid) in the proportions 8:2 (v/v) and 2:8 (v/v), respectively. The fractions eluted in buffer B $80 \%$, named stems $\mathrm{C}_{18 \_} 80 \% \mathrm{PV}$, leaves $\mathrm{C}_{18 \_} 80 \% \mathrm{PV}$ and $\mathrm{C}_{18 \_} 80 \% \mathrm{PL}$ showed the presence of masses in the range of 2900-3700 $\mathrm{Da}$ as analyzed by MALDI-TOF mass spectrometry (MS). To determine whether these fractions contained peptides with disulfide bonds, they were treated with the reducing agent $10 \mathrm{mM}$ dithiothreitol and alkylation agent $100 \mathrm{mM}$ iodoacetomide, and the mass increase of $348 \mathrm{Da}$ were observed, suggesting that three disulfide bonds had been reduced.

The $\mathrm{C}_{18} \_80 \%$ PL fraction was analyzed using LC-MS (HRESIMS) and was possible to find seven cyclotides; two of them are already described in the literature. 
A

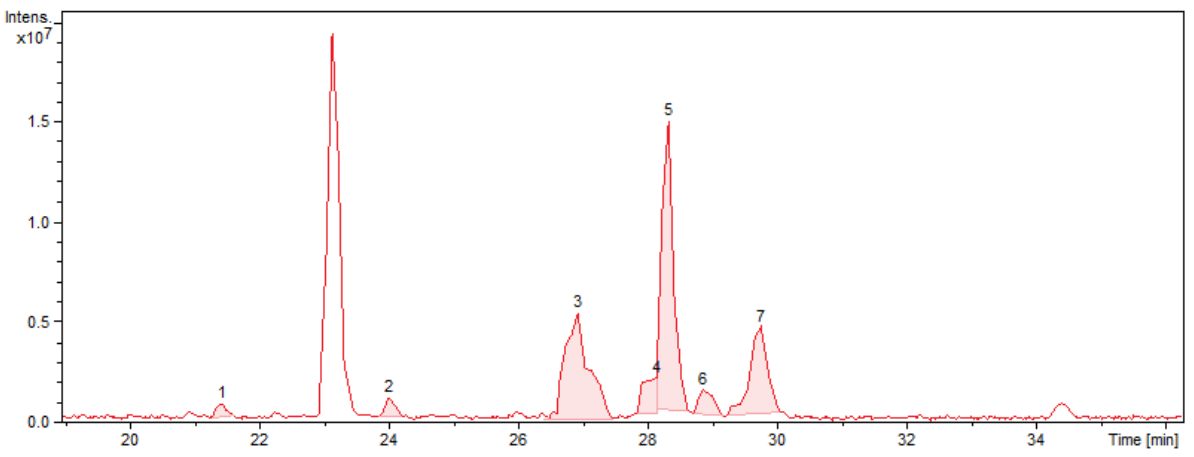

B

\begin{tabular}{ccccc}
\hline Mass & $\begin{array}{c}\text { Retention } \\
\text { time (min) }\end{array}$ & $\begin{array}{c}\text { Molecular Mass } \\
\text { (Da)* }\end{array}$ & Cyclotide & Reference \\
$\mathbf{1}$ & 21.3 & 3044.01 & - & \\
$\mathbf{2}$ & 23.9 & 3026.88 & - & \\
$\mathbf{3}$ & 26.6 & 2972.97 & - & \\
$\mathbf{4}$ & 27.8 & 2948.13 & Psyleio B & 3 \\
$\mathbf{5}$ & 28.1 & 2988.24 & Psyleio A & 3 \\
$\mathbf{6}$ & 28.7 & 2982.03 & - & \\
$\mathbf{7}$ & 29.2 & 3048.09 & - & \\
\hline
\end{tabular}

Figure 1: Putative cyclotides identified by LC-MS in $C_{18-} 80 \%$ PL from Psychotria leiocarpa. A) Base peak chromatography. B) Table showing each mass related with its retention time. $C_{18}$ Kromasil column $(250 \times 4.6$ $\mathrm{mm}, 5 \mu \mathrm{m}$; flow rate: $1 \mathrm{~mL}$ per min), $300 \AA$, linear gradient of $\mathrm{CH}_{3} \mathrm{CN}(25-65 \% \mathrm{~B}$ in $40 \mathrm{~min})$, and $\mathrm{UV} 220 \mathrm{~nm}$. Solvents: Buffer $\mathrm{A}\left(\mathrm{H}_{2} \mathrm{O} / 0.1 \% \mathrm{HCOOH}\right)$ and Buffer $\mathrm{B}\left(90 \% \mathrm{CH}_{3} \mathrm{CN} / 0.1 \% \mathrm{HCOOH}\right)$. *The masses shown are monoisotopic.

The leaves and stems $\mathrm{C}_{18}$ _80\% PV fractions were analyzed using LC-MS (HRESIMS) and were possible to find some cyclotides to both tissues.

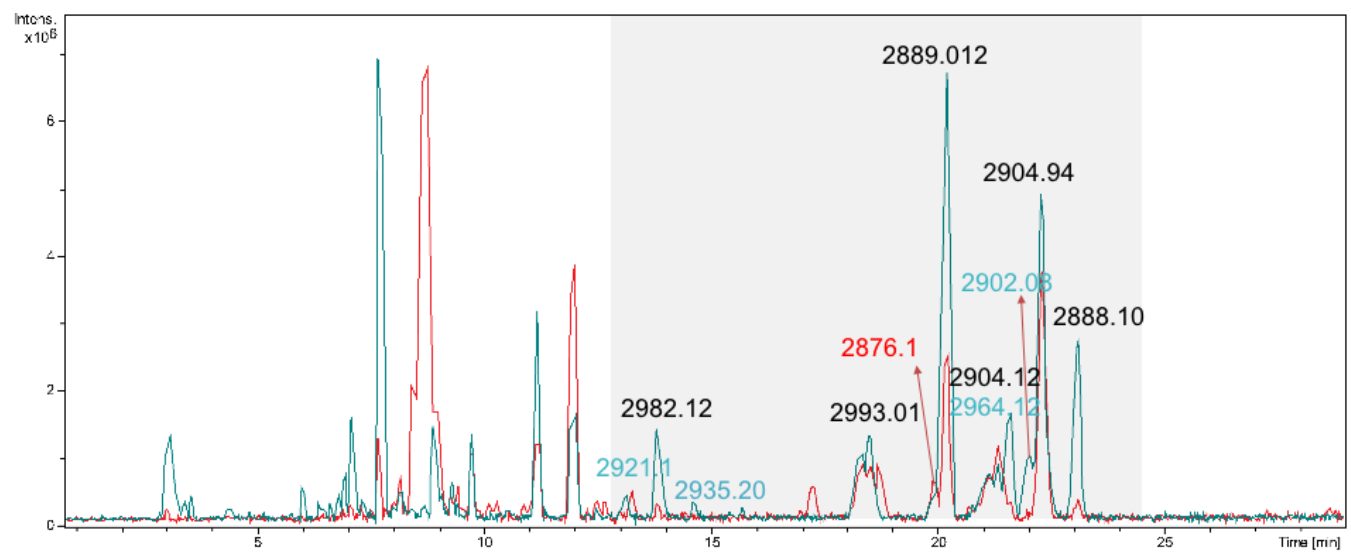

Figure 2: Putative cyclotides identified by LC-MS in leaves (red line) and stems (green line) $C_{18 \_} 80 \%$ PV fractions from Psychotria leiocarpa. Highlighted in gray, the region eluting putative cyclotides. The masses are represented in black when are common to both tissues, in green to stem-specific and in red to leave-specific.

From stems $\mathrm{C}_{18 \_} 80 \%$ PV were isolated the möbius cyclotides, with $\mathrm{m} / \mathrm{z} 2889$ and 2905 . The cyclotides sequencing were performed by reduction, alkylation and enzymatic digest with endoproteinases Glu-C and trypsin and followed by MS/MS analysis. The spectra were carefully examined and the sequences were proposed, based on the presence of both $b$ - and $y$-series of ions ( $N$ - and $C$-terminal fragments). The Ile and Leu are assigned on basis of homology. 

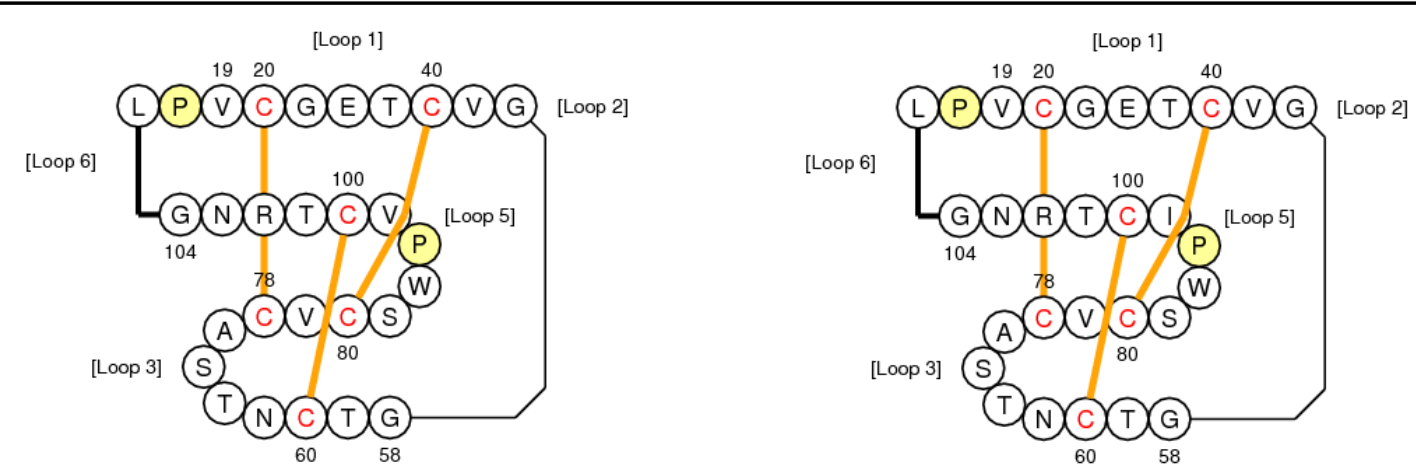

Figure 3: Cyclotides isolated from P. vellosiana. $\mathrm{m} / \mathrm{z}$ of 2889 and 2905, respectively.

Here, some cyclotides are identify to $P$. leiocarpa and $P$. vellosiana. From this last species, were possible to isolated and to sequence two novel möbius cyclotides. 